\title{
Implicit Referential Meaning with Reference to English Arabic Translation
}

\author{
Basem Al-Zughoul $^{1}$ \\ ${ }^{1}$ Zarqa University College, AL-Balqa Applied University, Al-Zarqa, Jordan \\ Correspondence: Basem Al-Zughoul, Zarqa University College, AL-Balqa Applied University, Al-Zarqa, Jordan. \\ E-mail: basemshukri@yahoo.com
}

Received: March 3, 2014 Accepted: May 20, 2014 Online Published: June 13, 2014

doi:10.5539/elt.v7n7p168 URL: http://dx.doi.org/10.5539/elt.v7n7p168

\begin{abstract}
The purpose of this study is to investigate how English implicit referential meaning is translated into Arabic by analyzing sentences containing implicit referential meanings found in the novel "Harry Potter and the Prisoner of Azkaban". The analysis shows that the translation of English implicit referential meaning into Arabic can be done implicitly or explicitly by paying attention to the references. It also shows that it is essential to come up with adjustments in translating sentences with implicit referential meanings if the meaning causes ambiguity or vagueness in the target language.
\end{abstract}

Keywords: implicit meaning, implicit referential meaning, formal equivalence

\section{Introduction}

\subsection{Background of the Study}

Not all of the meaning which is being communicated is stated overtly in the forms of the source language text. In this respect, Larson (1984) states that the "implicit meaning is a meaning that is not shown but it is the part of the conversation or intention to convey the speaker" (p. 36).

In translating process, translating implicit meaning can be a demanding task due to the fact that implicit meaning is not overtly seen. Therefore, implicit meaning needs to be treated appropriately because it has the implied information which the reader may not know. To make it clear, it has to be stated by the translator. In this vein, Larson (1984) states that "the implicit information is part of the meaning which is to be communicated by the translation, because it is part of the meaning intended to be understood by the original writer" (p. 38).

Another thing to mention is that the meaning conveying the implicit information has the implied message. This message is a part of the whole meaning. Therefore, the translation of implicit meaning may lead to misinterpretation of the target language because of the linguistic and cultural differences between the source and target languages. Besides, it can produce ambiguity or even vagueness in the target language.

In obtaining a good translation, translators are required not only to have a good command of the source language (SL) and the target language (TL), but they must understand language, culture and implicit meaning found in the source language and the target language.

A good translation is the one which conveys messages, thoughts, ideas, and concepts from the source language thoroughly and correctly. Larson (1998) states that an effective translation is the one that transfers the meaning of the source language into the target language by changing the form (lexicon and grammar) of the source language into the form of the target language. In other words, the original meaning must stay constant. This means that the form it takes in the target language does not matter. Furthermore, the target text should be in its natural forms and appropriately communicative in the sense that it can convey all the aspects of meaning which are readily understandable to the readers.

Hence, to be able to capture the implicit message properly, the translator must have the ability to recognize and translate the various kinds of meanings and ways of translating implicit meaning. In any text, sometimes the meaning is not conveyed explicitly. On the contrary, the reference to certain things, events or relations might be left implicit. The meaning does exist but it is not expressed explicitly.

Specifically, Larson (1984) classifies the implicit meaning into three categories: implicit referential meaning, 
implicit organizational meaning and implicit situational meaning.

This paper focused only on translating implicit referential meaning because it has the implied information which needs to be treated appropriately.

\subsection{Statement of the Problem}

Implicit referential meaning is often a source of difficulty for translators due to the fact that English and Arabic belong to two different language families and two different cultural backgrounds, which is reflected in the means of expression adopted by language users.

\subsection{Hypothesis of the Study}

The present study aims at testing these hypotheses:

1) It is hypothesized that implicit referential meaning in the source language is rendered implicitly into Arabic.

2) Formal equivalence is considered a favorable option in rendering implicit referential meaning in literary texts.

\section{Review of the Related Literature}

\subsection{The Concept of Equivalence}

Equivalence is a key concept in the process of translation because it determents which type of translation should be used to render a certain text. Farghal (1994) argues that "translation is a mode of communication where choices are further subjected to a principle of equivalence between a source text in one language and a target text in another" (p. 56).

\subsubsection{Formal Equivalence}

Formal equivalence derives its name from the fact that it focuses primarily on the form of the original. In other words, it is a translation procedure that attempts to retain the formal features of the original language in the translation process.

In general, formal equivalence is the closest possible match of form and content between SL and TL. As Nida (1964) puts it, it" ... focuses attention on the message itself, in both form and content" (p. 159).

\subsection{Implicit Meaning}

Not all of the meaning which is being communicated is stated overtly in the forms of the source language text. In this respect, Larson (1984) states that the "implicit meaning is a meaning that is not shown but it is the part of the conversation or intention to convey the speaker" (p. 36).

In the process of understanding the implicit meaning, the responders sometimes have to try hard to get the proper interpretation by the imagery or interpretation. Responders need to know certain things like reference, situation and context. Knowledge of context will help responders to get the right interpretation.

In an attempt to understand and achieve the correct message of a source language text, the terms of reading the line and reading between the lines should be maintained. Reading the line refers to reading with a view to know the explicit meanings, while reading between the lines means reading to know the implicit meanings.

\subsubsection{Implicit Referential Meaning}

According to Paltridge (2006) implicit referential meaning is "the situation where the identity of an item can be retrieved from either within or outside the text" (p. 131). In other words, the reference to certain things, events, attributes and relations might be left implicit, but the meaning is there but not expressed explicitly. In this vein, Baker (1992) states that "the term reference is traditionally used in semantics for the relationships, which holds between a word and what it points to in the real world" (p. 181). For example, if someone asks, "How many people came?" the person asked may answer, "Ten". In this context it is clear that "ten" means "ten people came". The reference to people and came is left implicit in the answer.

All languages have grammatical forms which are obligatory, but languages differ in what is obligatory. In English, it is obligatory to make the noun, whether singular or plural, explicit. For example, one can not say, "I saw dog walking down the street". One must say, "I saw a dog walking down the street". Number must be made explicit in English, but in many languages, including Arabic, it can be left implicit.

English has no difference in grammatical forms for masculine and feminine in the second person, but when translating from English into Arabic, it is obligatory to make this information explicit.

Which referential meaning is implicit and which is explicit will depend on the individual language. Since languages differ greatly in this matter, many adjustments will need to be made in translation. These will be 
discussed in more detail later in this research.

The three different types of implicit referential meaning; namely, personal reference, demonstrative reference and comparative reference, will be discussed in the following section.

Personal reference is a pronoun that refers to a particular person, group or a thing. It can take the place of nouns and noun phrases. In other words, the personal reference is a reference by means of function in the speech situation, through the categories of person. The category of personals includes the three classes of personal pronouns (I, he, she, it, you, they, we), possessive pronouns (mine, yours, his, hers, theirs, ours) and possessive adjectives (my, his, her, their, your, etc.)

Personal pronouns are considered to be the most typical example of reference in English. They are used to refer to persons within the same linguistic environment.

In Arabic, personal reference is divided into three categories, first person (ana), second person (anta, anti antuma, antum, antuna) and third person (huwa, heya, huma, hum).

Demonstrative reference is a reference by means of location. Halliday and Hasan (1976) argue that demonstrative reference is essentially a form of verbal pointing. The speaker identifies the referent by locating it on a scale of proximity.

Comparative reference is a type of implicit referential meaning. In this respect, Halliday and Hasan (1976) argue that it "is cohesion in the form of reference that shows comparison between one thing and another" (p. 76).

\section{Research Approach}

In this research descriptive analytical study is employed. This method is used in order to discover, identify, analyse and describe the sentences containing implicit referential meanings found in the novel "Harry Potter and the Prisoner of Azkaban" and the translation procedures used by the translator in translating the implicit meaning in the novel.

Fraenkel and Wallen (1993), in this regard, argue that the descriptive method is "a method to explain, analyse and classify something through various techniques, survey, interview, questionnaire, and a test" (p. 33).

To this end, there will be a description of data from the source novel "Harry Potter and the Prisoner of Azkaban" by J. K. Rowling as well as from the product of the translation by Ahmad Hasan Mohammed. Then a complete description of how implicit meaning in English was translated in Arabic will be given.

\section{Results}

The translation of English implicit referential meaning into Arabic can be done implicitly or explicitly by paying attention to the reference. An implicit translation can be done if the entailments of anaphoric references are clear and understandable without causing ambiguity and without sacrificing the unity of meaning. To illustrate this point, let us consider the following examples:

Data 1.a

Data 1.b

Harry went down to breakfast next morning to find the three Dursleys already sitting around the kitchen table. They were watching a brand-new television... (p. 22).

Wa fi sabah alyawn altali tawajaha harry le tanawul aleftar fawajada al Dursleys Jaleseen hawala maedat almatbak le ushahedu jehaz altelfaz (p. 18).

In the example above, the referent of the pronoun "They" is implicit. It functions as a subject of the sentence and has a reference of "the three Dursleys" mentioned in the previous sentence. Here, the translator opted for translating the pronoun implicitly as (ushahedu).

Data 2. a

Harry Potter was a highly Unusual boy in many ways. For one thing, he hated the summer holidays more than any other time of the year ( $p .7)$.

\section{Data 2. $b$}

Lam yakun Harry waladan adyan methel baqeyat alawlad, faqad kana yakhtalef anhum fi katheer min alumur. Fahuwa methalan... (p. 3)

In this sentence above, the referent of the pronoun "he" is implied. The pronoun signifies a masculine third person and has a reference of "Harry Potter". Therefore, the translator opted for translating the subject pronoun implicitly as (huwa). This translation is clear because the reference is stated in the previous sentence.

Data 3. a

"Boggarts like dark, enclosed spaces,"... This one moved $n$ yesterday afternoon, and I asked. (p. 145)
Data 3. $b$

In Boggarts uheb alamaken almughlagah, wlaqad taharak huna... (p. 139) 
The demonstrative pronoun "this" in the above example functions as a modifier to the head "one". The word "this", which refers anaphorically to something the speaker himself has said, is limited to one Bogart mentioned in the previous sentence. Here the translator opted for translating the demonstrative "this" implicitly by deleting the demonstrative pronoun. This translation is clear because the referent is mentioned in the previous sentence.

\section{Data 4. a}

Data 4. $b$

"I would like to speak to Harry and Hermione alone," said Dumbledore abruptly..." "This cannot wait," said Dumbledore. "I must insist." (p. 421).

Ana ureedu altahduthu ma Harry wa Hermione bemufradena. Qala Dumbledore: hatha la umken tajeeluh (p. 388).

The demonstrative pronoun "this" regularly refers anaphorically to something that has been said before; a speaker uses "this" to refer to something he himself has said. Therefore, the demonstrative "this" refers to the speaker's desire of speaking to Harry and Hermione alone. In Arabic the translator opted for keeping the demonstrative pronoun implicit as (hatha). This translation is clear and captured in the target language because the referent is mentioned in the previous sentence, so it will be redundant to repeat the referent explicitly.

Data 5. a

For one thing, he hated the Summer holidays more than any other time of the year ( $p .7)$.
Data $5 . b$

Fahuwa yakrah alutlah alsayfeyeh akthar min aya waqtin mada (p. 3).

The example above has an implicitness of comparative reference "more than". The comparative reference compares two nouns: the summer holiday and other time of the year. The translator opted for translating the comparative reference explicitly as (akther men aya waqtin mada).

Data 6. a

Harry jumped up out of the bed; Hermione had done the same (p. 419).
Data 6. $b$

Qafaza Harry min ferasheheh wa kathaleka fa'alat Hermione (p. 386).

Example 6. a has an implicitness of comparative reference "the same". The comparative reference "the same" refers to the two events: the first one is that Harry jumped up out of the bed. The second one is that Hermione jumped up out of the bed. The comparative reference in 28.a. is a cohesive device used to avoid repeating the same words within the sentence. The translator opted for keeping the referent implicit to avoid repetition as well.

Sometimes an implicit translation of anaphoric reference causes an ambiguity because of the far-distant location of the referent as shown by the following example,

\section{Data 7. $a$}

So she phoned the telephone hotline. By the time the Ministry of Magic got there, he was gone. (p. 139)
Data 7.b

Lethaleka faqad itasaltu fi alkhat alsakhen, waendama hadarat wizarat alseher kana qad thahab. (p. 134)

In this sentence the personal pronoun "he" is a subject, which has an implicit meaning and a reference of Black. Unfortunately, the name of the man who was left implicit here is not mentioned in the previous sentence; it is mentioned in the previous two paragraphs. Therefore, keeping the implicit meaning of "he" in Arabic made the translation unclear and not understandable. The Arabic reader might think that the pronoun "he" refers to the reference of "Harry" or "Black". The translator should have made the implicit meaning explicit by saying "Kana Black qad thahab" in order to avoid the uncertainty caused by the far-distant location of the referent.

As far as cataphoric references are concerned, an implicit translation can be done if the entailments of cataphoric references are clear and understandable without causing ambiguity and without sacrificing the unity of meaning. To illustrate this point, let us consider the following examples:

Data 8. a

And, sir, I'll need this skinned, said Malfoy, his voice full of malicious laughter (p. 136).

\section{Data $8 . b$}

Qala Malfoy wasawtuhu yafouh belmaker: saydi sa'ahtaju aydan ila taneem hatheh alawraq (p. 131).

The example 8. a has a subject pronoun "I" which has an implicit referent. It refers cataphorically to the referent "Malfoy". The translator opted for translating the pronoun "I" implicitly by omitting the pronoun and replacing it with a letter (alif) in the word "sa'ahtaju". In 8.b. the translation is clear because a personal pronoun can be omitted and replaced by a letter when it is used as a subject of a full verb. Here, the subject (I ) is ellipted obligatorily in (sa'ahtaju) because the bound morpheme (alif ) serves as an explicit reference to the concealed pronoun (ana). 
Data 9. a

Professor McGonagall opened the classroom door at that moment, which... (p. 162).
Data 9. $b$

Min husun alhadh an'a alustatheh McGonagall fatahat bab alfasel fi telka alahdha (p. 156).

Example 9. a has a demonstrative pronoun "that" which refers cataphorically to the referent "moment". The demonstrative "that" is associated with a past- time referent. Here the translator opted for translating it implicitly as (telka).

Data 10. a

"They're horrible things, those Dementors ..." (p. 108).

Example 10. a has a demonstrative reference "those" which refers cataphorically to the count plural "dementors". The demonstrative "those" with a following noun refers just to the presupposed item "dementors". In translation, the translator kept the demonstrative adjective implicit. This translation is easily captured in the target language.

However, an explicit translation should be put into consideration if an implicit translation will make the translation of references unclear or ambiguous. The following examples will prove this point:

Data 11. a

Data 11. b

It was nearly midnight, and he was lying on his Kana alwaqet muntasaf alayel taqreeban, waqad istalqa front bed... (p. 7).

Harry ala firasheh (p. 3).

The sentence has a personal pronoun "he" which has an implicit referent and a reference of "Harry". Translating this pronoun implicitly will confuse the reader because the referent is not mentioned in the previous sentence. It has a far-distant referent, so the only solution is to be translated explicitly in Arabic. The translator opted for this choice in rendering the personal pronoun "he" into "Harry". Therefore, this translation is clear and captured easily in the target language.

Data 12. a

Neville's lips moved, but no noise came out. “Didn't catch that, Neville, sorry.”... (p. 147).

\section{Data $12 . b$}

Taharkat shafata Neville doun a yasdur anhu aya sawt, fa qala almulem: afwan ana lam asma'a ma qulta (p. 141).

This example above has a demonstrative reference "that". It refers to the speech made by Neville in the previous sentence. In the translation process, the reference can be made explicit or implicit. When elected to be made implicit, then the sentence would be (ana lam asma'a thalek). Here, the translator chose the reference to be made explicit, so translating the phrase as (ana lam asm'a ma qulta) makes the sentence clearer and the meaning is easily understood.

\section{Data 13. a}

In one hand she held an enormous suitcase, and tucked under the other was and old and evil-tempered bulldog (p. 30).

The example 13. a has an implicitness of comparative reference "the other". The comparative reference refers anaphorically to something that has been said before and compares two things. It can be seen form the sentence that the referring expression "the other" refers to the word hand. The translator here opted for translating the referent explicitly to in order convey the clear meaning.

\section{Data 14. a}

Harry was bursting to say that he'd rather live in an orphanage than with the Dursleys (p. 31).

\section{Data 13. $b$}

Wa fi ehda yadyhaa kanat tahmel haqeebah, wa fi alyad alukhra uwjad thaleka alkalb alshereer "bulldog” (p. 25).

The example 14. a has an implicitness of a comparative reference "rather than". This referring expression has a reference of "living in an orphanage". It functions as comparing between living in an orphanage and living with the Dursleys. The translator her opted for translating the referent explicitly as "afdhal bekatheer min baqaeheh wasat al Dursleys". This translation is clear because the referent is made explicit.

As for exphoric reference, translating it implicitly will cause an ambiguity because it does not refer to any identity in the text, so an explicit translation will present itself as a valid option. Let us consider this example 
Data 15. a

It was nearly midnight ...h (p. 7).
Data 15. b

Kana alwaqt muntasaf alyal (p. 6).

The example 15. a has the pronoun "it" which does not refer to any identity in the text. This type of reference is exophoric. The pronoun "It" refers only to an identity that is in the context of the situation. Here, the translator opted for translating the pronoun explicitly into Arabic as "alwaqt" in order to make the meaning clearer.

\section{Discussion}

We can now draw the various threads together and try to test the hypotheses of the research. The study conducted has shown that most of the English implicit referential meaning data are translated into Arabic implicitly because the system of the target language allows that. In other words, both English and Arabic languages can use the implicit reference whether it is in the form of personal, demonstrative or comparative. This conclusion validates hypothesis number (1).

As for the second research hypothesis of selecting a type of equivalence that is considered a favorable option in rendering implicit referential meaning in literary texts, the example has shown that the translator tends to use the first option of literal translation approach in the translation process and hence translate the source language implicit references into implicit references in the target language. This amounts to saying that this translation alternative can be considered to be the default situation which is expressed in the absence of any restrictions which oblige translators to resort to the other translation alternative options. As a result of this technique, it can be said that formal equivalence is preserved in case of implicit referential meaning because it is the closest possible match of form and connect between SL and TL. As Nida (1964) puts it, it "... focuses attention on the message itself, in both form and content" (p. 159).

\section{Conclusion}

The conclusions of this thesis of implicit meanings are as follows:

1) An implicit meaning can be translated implicitly if the entailment of references is clear and understandable; if the target language has grammatical system which allows it; if the implicit meaning is familiar and comprehensible by the target readers.

2) An implicit meaning should be translated explicitly if it causes ambiguity or vagueness in the target language.

\section{Suggestions and Recommendations}

\subsection{Recommendations}

In light of the results of the study, the researcher offers the following recommendations:

1) This study can be a useful guidance in having a field research about measuring the tendency of translating implicit referential meaning, whether the tendency lies in translating it explicitly or implicitly.

2) More attention should be paid to the subject of implicit referential meaning by allocating parts of a text book to throw light on the problem, types of implicit meaning and presenting ways of translating them.

\subsection{Suggestions for Further Research Works}

1) A contrastive study of implicit referential meaning in both English and Arabic might be conducted by investigating the differences and similarities of both languages.

2) The present study has investigated the translation of implicit referential meaning from English into Arabic. Another research could be conducted to investigate the other direction.

\section{References}

Baker, M. (1992). In other words: A Course book on Translation. London: Routledge.

Farghal, M. (1994). Managing in Translation: A Theoretical Model. Meta, 38(3).

Franenkle, J. R., \& Wallen, N. E. (1990). How to design and Evaluate: Research in Education. New York: McGraw-Hill.

Halliday, M., \& Hasan, R. (1976). Cohesion in English. London \& New York: Longman.

Larson, M. L. (1984). Meaning Based Translation: A Guide to Cross Language Equivalent. Boston: University Press of America.

Nida, E. A. (1964). Towards a Science of Translation. Leiden: E. J. Brill.

Paltridge, B. (2006). Discourse Analysis. London: Continuum. 
Yule, G. (1996). Pragmatics. New York: Oxford University Press.

\section{Copyrights}

Copyright for this article is retained by the author(s), with first publication rights granted to the journal.

This is an open-access article distributed under the terms and conditions of the Creative Commons Attribution license (http://creativecommons.org/licenses/by/3.0/). 